\title{
Determining Optimal Parameters of Regular Microrelief Formed on the End Surfaces of Rotary Bodies
}

\author{
Volodymyr Dzyura ${ }^{1}$ (D), Pavlo Maruschak ${ }^{1, *(D)}$ and Olegas Prentkovskis ${ }^{2}$ (D) \\ 1 Department of Motor Vehicles, Ternopil Ivan Puluj National Technical University, 46001 Ternopil, Ukraine; \\ volodymyrdzyura@gmail.com \\ 2 Department of Mobile Machinery and Railway Transport, Vilnius Gediminas Technical University, Plytinès g. \\ 27, LT-10105 Vilnius, Lithuania; olegas.prentkovskis@vilniustech.lt \\ * Correspondence: maruschak.tu.edu@gmail.com
}

check for

updates

Citation: Dzyura, V.; Maruschak, P.; Prentkovskis, O. Determining Optimal Parameters of Regular Microrelief Formed on the End Surfaces of Rotary Bodies. Algorithms 2021, 14, 46. https://doi.org/ $10.3390 /$ a14020046

Received: 8 January 2021

Accepted: 25 January 2021

Published: 30 January 2021

Publisher's Note: MDPI stays neutral with regard to jurisdictional claims in published maps and institutional affiliations.

Copyright: (C) 2021 by the authors Licensee MDPI, Basel, Switzerland. This article is an open access article distributed under the terms and conditions of the Creative Commons Attribution (CC BY) license (https:// creativecommons.org/licenses/by/ $4.0 /)$.

\begin{abstract}
The analytical dependences for determining the overlap area of V-shaped grooves of partially regular microrelief shifted by an angular pitch of $0.5^{\circ}$ are established. The $\mathrm{V}$-shaped grooves are formed on the end surface of the rotary body by vibration. In addition, the intersection between groove elements can be of different types. The relationship between the geometric parameters of $\mathrm{V}$-shaped grooves and their location is determined. The influence of geometrical parameters of grooves on the overlap area is established depending on their location. Measures are proposed to ensure that the burnishing area is the same at different distances from the center of rotation of the rotary body end surface on which the partially regular microrelief is formed. A graph showing the dependence of the overlap area of two grooves on the axial pitch between them is constructed, and a block diagram of the algorithm for determining the optimal value of the axial pitch is developed.
\end{abstract}

Keywords: partially regular microrelief; optimal value; algorithm

\section{Introduction}

End surfaces of rotary bodies are widely used as working surfaces of actuators in modern automotive and mechanical engineering. These include conical disks of continuously variable transmission of automatic transmissions of cars, parts of end bearings (both tapered and axial) [1-4], valves of gas-distributing mechanisms of internal combustion engines, and so on. These surfaces are usually exposed to high operating temperatures and specific pressures $[5,6]$.

Using plastic deformation of the surface to form a regular microrelief on the conjugated working surfaces of heavily loaded friction pairs allows enhancing their durability [7-10].

Fundamental in terms of findings obtained in the study of the influence of rolling modes on the surface layer structure of the treated surface is work [11]. The authors established the influence of burnishing force and rolling feed on the roughness parameters of the rolled surface. In addition, the authors investigated residual stresses in-depth (in the axial direction) at different feed rates of rolled materials (prediction of residual stresses (in the axial direction) for different burnishing feed rates, along with depth).

The result of comparing the structure of the material obtained by ball burnishing and shifted in the axial direction of the roller allowed us to systematize the influence of technological parameters and structural components of the material.

Specific parameters of the relative area of burnishing are challenging to provide when grooves of partially regular microrelief (PRMR) of the 3rd type are formed, which are characterized by an overlap of the groove. Therefore, the formation of PRMR of the 3rd type with a given relative area of burnishing on the rotary body end surfaces (RBES) is a rather complex technological task.

The formation of a regular microrelief on the conjugated working surfaces of heavily loaded friction pairs significantly enhances their functional properties and, accordingly, the 
service life of the unit itself [12-14]. The regular microrelief's positive effect on the surface roughness parameters is also described in [15]. A regular microrelief was formed on the outer cylindrical surfaces of specimens from medium-carbon steel 1C45 and low-carbon alloy steel 18CrMn4-4, which were used to determine the effect of processing conditions on the surface roughness and hardness. One of the leading research findings was that a significant influence of the vibration amplitude was found to be the most determining factor for the surface roughness parameter $R_{a}$.

In [16], the effect of changes in the deformation force and feed rate on the surface roughness parameters during burnishing and the mechanical properties of the surface layer was investigated. In addition, surface parameters obtained by ball burnishing and milling were compared. The range of optimal pressure values at the processing of specimens by ball burnishing (ball burnishing treatment), at which values of roughness parameters will be minimal, was established.

In [17], the relative area of the regular microrelief (RMR) $F_{n}$ was presented as the ratio of the area occupied by regular roughness $F_{g r}$ to the surface area of the part to be processed $F_{w}$. According to [1], the relative surface area $F_{n}$ was a partially regular microrelief parameter, which most fully characterizes almost all the surface's functional properties and, primarily, the actual contact area of one surface.

Therefore, the regular microrelief Fn's relative surface area was one of its most important indicators, which characterizes the working properties of the surface on which it is formed. Its optimal value varies between $30-45 \%$ depending on the conjugated surfaces' operating conditions [18]. The optimal relative areas of burnishing of the regular microrelief depending on the operating conditions of the machine parts' cylindrical surfaces were studied in detail in [19-21]. Such relative areas of burnishing are determined by the optimal value of the relative reference length of the profile top [22]. This value is defined as the ratio of the reference length of the profile to its base length. The AbbottFirestone curve can describe the relationship between surface performance and roughness parameters. This relationship was described in [23]. The performance characteristics of the surface were evaluated not by the surface roughness, but the parameters of the AbbottFirestone curve. According to the authors, the above three parameters determined from the Abbott-Firestone curve $\left(R_{p k}, R_{k}\right.$ and $\left.R_{v k}\right)$ illustrate the surface texture's ability to resist friction.

Peculiarities of evaluating the surface condition by the Abbott-Firestone curve parameters are described in [24]. The authors have found that surface integrity illustrates the relationship between the surface's required functional properties and changes in the new surface properties. The surface can be evaluated using two fundamental properties: The spatial arrangement of the surface (surface roughness) and the surface layer's physicochemical properties. To determine the burnishing area of a partially regular microrelief of the 3rd type formed on the rotary body end surface with V-shaped grooves, which were shifted by an angular pitch of $0.5^{\circ}$, it was necessary to determine the overlap area of PRMR grooves [25]. PRMR grooves of the 3rd type with a large degree of overlap significantly reduce the microrelief's total area and, accordingly, the relative area of vibration. Studies in this area focus mainly on determining the relative area of burnishing and the influence of the grooves' geometric parameters and arrangement.

In $[26,27]$, the formation of a regular microrelief on profile surfaces with different geometric parameters depending on the formation conditions was considered. The authors conducted a full-factor experiment with four variables: The diameter of the deforming element, the deformation force, the amplitude of the deforming element, and the number of oscillations. According to the research findings, Pareto histograms were constructed, which show that the number of oscillations and the deforming element amplitude significantly influence changes in the shape of the regular microrelief cells.

The authors of [28] presented the results obtained with the experimental tool L8 Taguchi, which was used to form a regular microrelief on planar surfaces. The parameters that significantly affect the process of forming a regular microrelief using a CNC milling 
machine on flat surfaces were determined. By changing the processing modes, regular microreliefs of different sizes were formed, on which the orientation of grooves was different. Such an element of the forming mode as the feed was also used.

A comparative analysis of different types of regular microrelief was conducted subject to the condition of forming the largest area of contact with the liquid [29]. RMR types, such as concave cones, spherical holes, and longitudinal lines, were compared. It was found that with other identical parameters, the microrelief represented by conical holes was the most optimal. The smallest area of contact with the liquid was provided by a microrelief represented by a plurality of holes of concave spherical shape. The area of triangular grooves, depending on the groove's geometric parameters and their location on the rotary body end surfaces, was calculated in [30].

The authors of [31], Barauskiene O. and Zyhulia S., developed an algorithm for the technological process of forming geometric parameters of a partially regular microrelief by burnishing on the outer cylindrical surface of printing equipment. The influence of technological factors on changes in the surface area with partially regular microrelief was established. The limits and conditions of possible variation of the relative surface area were determined to enhance the performance of the printing equipment parts. In [32], the control algorithm was developed for the technological process of forming microrelief guides by a method of fine plastic deformation applied to flat surfaces of the printing equipment parts. The proposed technology allows increasing the wear resistance of flat guides and improving printed products' positioning when passing the surface of micro guides of printed products. The developed algorithm includes a set of indicators related to the material, geometric, and physicomechanical parameters of the flat guide surface and plastic deformation conditions.

The problem of the overlap of the groove area was considered in [33]. However, the author considered a sinusoidal type groove, which was approximated as a set of rectilinear sections. This method of approximation is quite inaccurate to determine the area of overlap. After analyzing scientific publications in the public domain, we can conclude that no studies have been carried out to determine the overlap area of V-shaped grooves formed on the regular or partially regular microrelief.

This research aims to determine the overlap area of the PMR grooves formed on the RBES and the influence of mutual placement and geometric parameters of the grooves.

\section{Materials and Methods}

According to [17], regular microreliefs and [25] partially regular microreliefs were classified as follows: Type I-microreliefs with non-intersecting grooves, Type II-with tactile grooves, Type III-with intersecting grooves.

The technological scheme of forming a partially regular microrelief of type III with V-shaped grooves on the rotary body end surfaces with molding movements is shown in Figure 1.

According to the classification presented in [25], the grooves' mutual arrangement, the location of the axial lines of symmetry of the grooves, and the shape of the grooves were the classification features of the PRMR grooves formed on the RBES. Overlap area $S_{o v}$. was the regular microrelief parameter, which characterized the mutual placement of intersecting microrelief grooves. On the other hand, the overlap area was the area of impressions formed by groove surfaces, which was common for the grooves shifted by the axial pitch. 


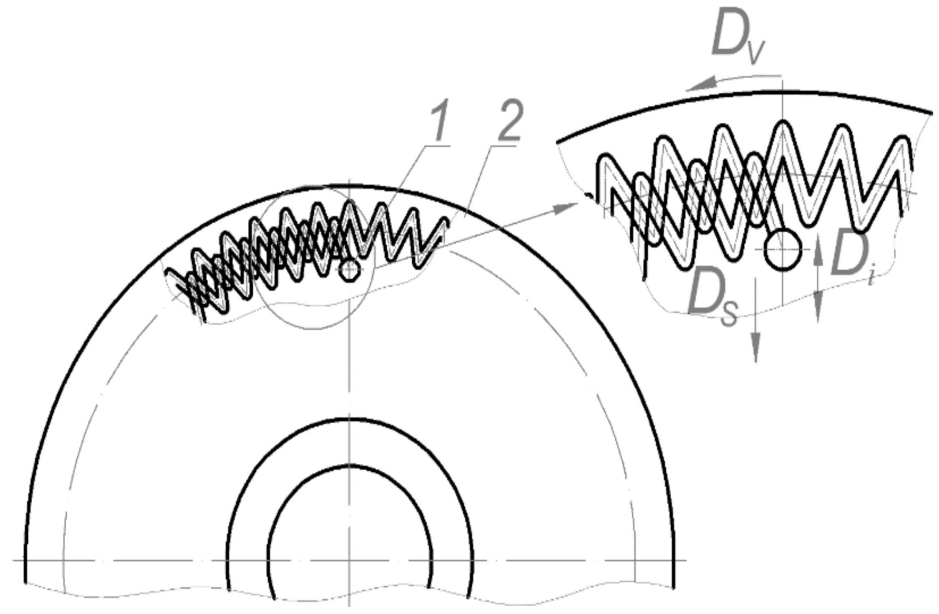

(a)

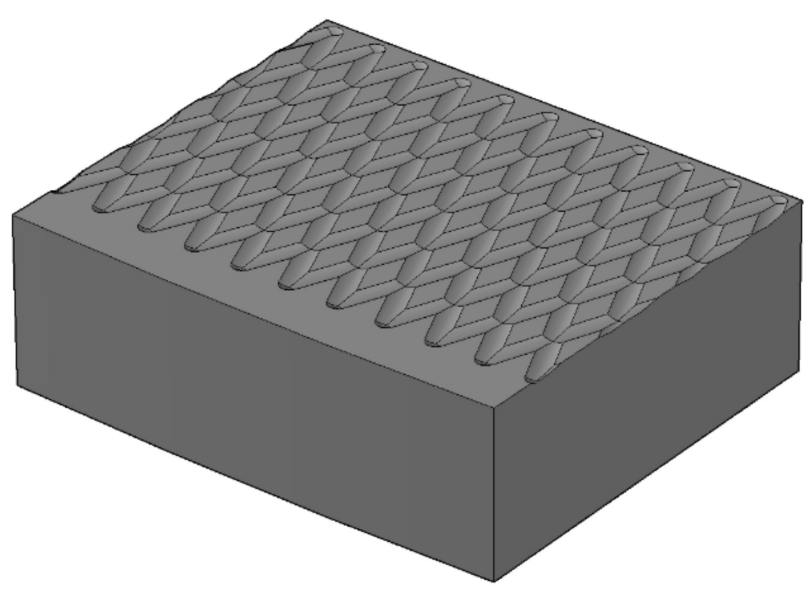

(b)

Figure 1. Partially regular microrelief formed on the disk: (a) Formation scheme with molding movements; (b) visual image; 1 -deforming element; 2 - end surface of the variator disk; $D_{v}$-rotational movement of the disk; $D_{s}$-tool feed movement; $D_{i}$ - the oscillating reciprocating motion of the tool.

\section{Results}

Consider the general case of the intersection of V-shaped grooves formed on rotary bodies' end surfaces (Figure 2). This will help us establish the dependent geometric parameters of the grooves and the relationship between them.

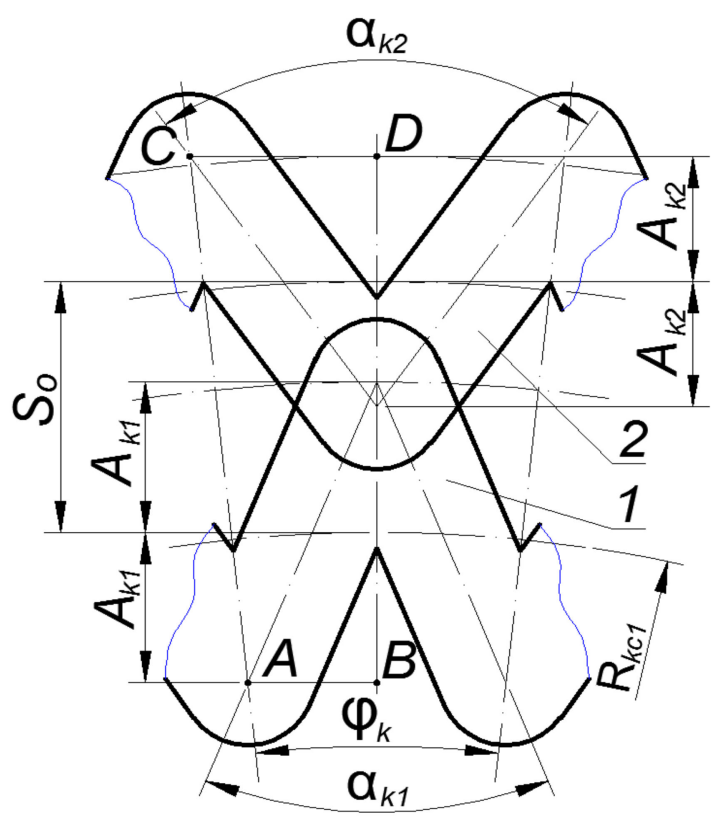

Figure 2. The general case of the intersection of partially regular microrelief (PRMR) grooves formed on rotary body end surfaces (RBES): $A_{k 1}$-amplitude of groove 1, mm; $A_{k 2}$-amplitude of groove $2, \mathrm{~mm} ; S_{0}$ - the axial pitch of the grooves, $\mathrm{mm} ; \alpha_{k 1}$-the angle of the element of groove 1 formed on RBES with radius $R_{k c 1}$, degrees; $\alpha_{k 2}$-the angle of the element of groove 2 formed on RBES with radius $R_{k c 2}$, degrees; $\varphi_{k}$-angular step of PRMR grooves, degrees; $\rho_{k}$-imprint radius of the PRMR deforming element (groove width).

The relationships between groove parameters were as follows: 
The angular pitch of the groove is determined from the equation:

$$
\varphi_{k}=\frac{360^{\circ}}{N_{e l}}
$$

where $N_{e l}$ is the number of PRMR elements located on the RBES within the range of $360^{\circ}$.

We write down the equation for determining the angle $\alpha_{k 1}$

$$
\left\{\begin{array}{l}
A B=\left(R_{k c 1}-A_{k 1}\right) \cdot \operatorname{tg}\left(\varphi_{k} / 2\right) \\
A B=2 \cdot A_{k 1} \cdot \operatorname{tg}\left(\alpha_{k 1} / 2\right)
\end{array}\right.
$$

Having solved the system of equations to determine $\alpha_{k 1}$, we obtain:

$$
\alpha_{k 1}=2 \cdot \operatorname{arctg}\left[\frac{\left(R_{k c 1}-A_{k 1}\right) \cdot \operatorname{tg}\left(\varphi_{k} / 2\right)}{2 \cdot A_{k 1}}\right]
$$

Similarly, we write down the equation to determine the angle $\alpha_{k 2}$ :

$$
\left\{\begin{array}{l}
C D=\left(R_{k c 1}+S_{o}+A_{k 2}\right) \cdot \operatorname{tg}\left(\varphi_{k} / 2\right) \\
C D=2 \cdot A_{k 2} \cdot \operatorname{tg}\left(\alpha_{k 2} / 2\right)
\end{array}\right.
$$

Having solved the system of equations to determine $\alpha_{k 2}$, we obtain:

$$
\alpha_{k 2}=2 \cdot \operatorname{arctg}\left[\frac{\left(R_{k c 1}+S_{o}+A_{k 2}\right) \cdot \operatorname{tg}\left(\varphi_{k} / 2\right)}{2 \cdot A_{k 2}}\right]
$$

In addition, we can express angle $\alpha_{k 2}$ via angle $\alpha_{k 1}$. To do this, we make a system of equations from system of Equations (2) and (3).

$$
\left\{\begin{array}{l}
2 \cdot A_{k 1} \cdot \operatorname{tg}\left(\alpha_{k 1} / 2\right)=\left(R_{k c 1}-A_{k 1}\right) \cdot \operatorname{tg}\left(\varphi_{k} / 2\right) \\
2 \cdot A_{k 2} \cdot \operatorname{tg}\left(\alpha_{k 2} / 2\right)=\left(R_{k c 1}+S_{o}+A_{k 2}\right) \cdot \operatorname{tg}\left(\varphi_{k} / 2\right)
\end{array}\right.
$$

Having solved this system of equations to determine $\alpha_{k 2}$, we obtain:

$$
\alpha_{k 2}=2 \cdot \operatorname{arctg}\left[\frac{0.5 \cdot\left(A_{k 1}+A_{k 2}+S_{o}\right) \cdot \operatorname{tg}\left(\varphi_{k} / 2\right)+A_{k 1} \cdot \operatorname{tg}\left(\alpha_{k 1} / 2\right)}{A_{k 2}}\right]
$$

Thus, the obtained dependencies allow us to express the required geometric parameters using known quantities.

When analyzing the groove intersection process, seven stages of the intersection were found. In addition, the degree of overlap transforms from the intersection of the segmental parts of vertices to a complete intersection of rectilinear sections of the grooves.

Analytical dependences to determine the overlap area will be different at each stage, thus we consider each case separately.

It should also be noted that the overlap area of the grooves for cases I-IV was defined as the area of a complex figure formed by segments and trapezoids. The number of such areas will be equal to half the number of intersecting grooves.

For cases V-VII, the overlap area was defined as the area of intersecting diamonds. The number of such areas will be equal to the number of intersecting grooves.

Stage I. Consider the case when the groove vertices intersect within a circular segment with radius $\rho_{k}$ and chord height $\Delta_{\rho}$ (Figure 3). 


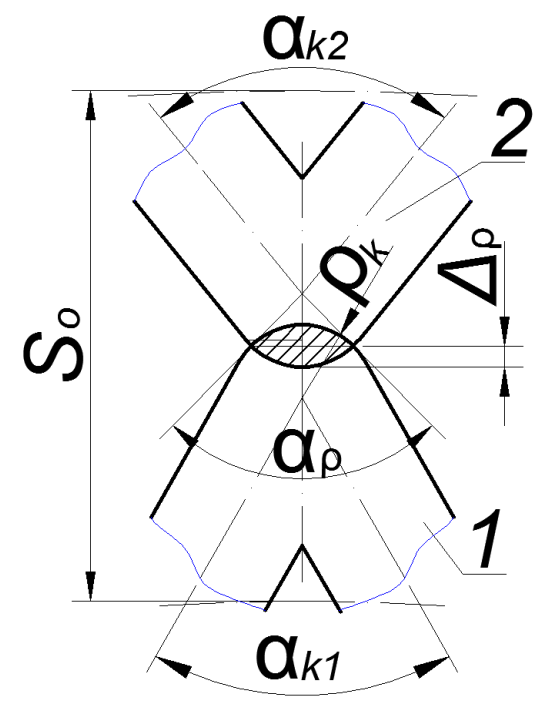

Figure 3. Scheme of overlap of V-shaped grooves of PRMR (stage I).

The overlap area of two grooves was defined as the sum of their segments' areas with the chord height $\Delta_{\rho}$.

$$
S_{o v}=\rho_{k}^{2} \cdot\left[\frac{\pi \cdot \alpha_{\rho}}{180^{\circ}}-\sin \alpha_{\rho}\right]
$$

The formula determines the chord height:

$$
\Delta_{\rho}=\frac{2 \cdot \rho_{k}-S_{o}+A_{k 1}+A_{k 2}}{2}
$$

where $\rho_{k}$ is the segment radius, $\mathrm{mm}$; $S_{o}$ is the axial pitch of PRMR grooves, $\mathrm{mm}$; $A_{k}$ is the amplitude of PRMR grooves, $\mathrm{mm}$.

The formula determines angle $\alpha_{\rho}$ :

$$
\alpha_{\rho}=2 \cdot \arccos \left(\frac{S_{o}-A_{k 1}-A_{k 2}}{2 \cdot \rho_{k}}\right)
$$

Taking into account (10), Formula (8) takes the following form:

$$
S_{o v}=\rho_{k}^{2} \cdot\left[\frac{2 \cdot \pi \cdot \arccos \left(\frac{S_{o}-A_{k 1}-A_{k 2}}{2 \cdot \rho_{k}}\right)}{180^{\circ}}-\sin \left(2 \cdot \arccos \left(\frac{S_{o}-A_{k 1}-A_{k 2}}{2 \cdot \rho_{k}}\right)\right)\right]
$$

The area of existence for this formula was determined by the limit value of the axial pitch of the PRMR, which was determined from the following dependence:

$$
\left\{\begin{array}{c}
A_{k 1}+A_{k 2}+2 \cdot \rho_{k}>S_{o} \geq A_{k 1}+A_{k 2}+2 \cdot \rho_{k} \cdot \sin \left(\frac{\alpha_{k 2}}{2}\right) \\
\alpha_{k 2}>\alpha_{k 1}
\end{array}\right.
$$

Stage II. Consider the case when the groove vertices intersect within the circular segment with radius $\rho_{k}$ and chord height $\Delta_{\rho_{1}}$ and partially rectilinear sections (Figure 4). 


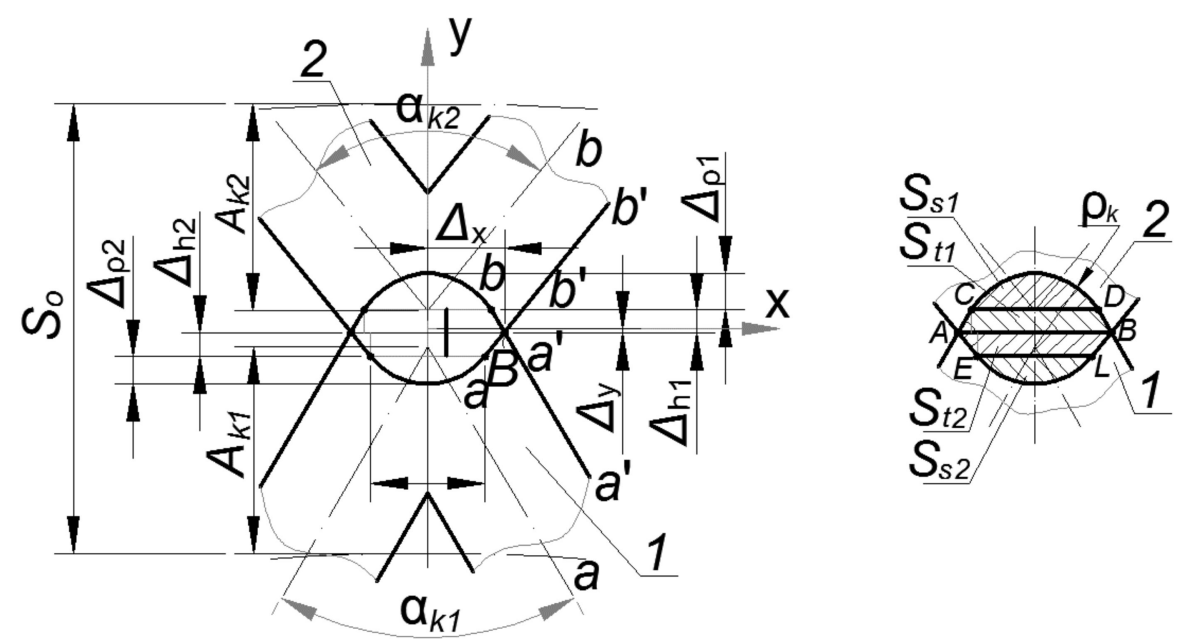

Figure 4. The scheme of overlapping of V-shaped grooves of PRMR (stage II).

We calculated the overlap area of the grooves for this case.

In this case, the overlap area will be defined as the sum of the areas of two circular segments with radius $\rho_{k}$ and the areas of two trapezoids (ACDB and AELB) (Figure 4).

$$
S_{o v}=S_{s 1}+S_{s 2}+S_{t 1}+S_{t 2}
$$

where $S_{s 1}$ is the segment area of groove $1, \mathrm{~mm}^{2} ; S_{t 1}$ is the trapezoid area of groove $1, \mathrm{~mm}^{2}$; $S_{s 2}$ is the segment area of groove $2, \mathrm{~mm}^{2} ; S_{t 2}$ is the trapezoid area of groove $2, \mathrm{~mm}^{2}$.

To determine the overlap area according to the scheme (Figure 4), it was advisable to determine the coordinates of point $B$ pertaining to the intersection of groove elements.

To do this, we wrote down the equation of the axial lines of grooves 1 and 2 in the coordinate system $x y$.

The equation of centerline $a-a$ (groove 1 ) is written in the following form:

$$
y_{i(a-a)}=\operatorname{tg}\left(90-\frac{\alpha_{k 1}}{2}\right) \cdot x_{i}+\frac{S_{o}-A_{k 1}-A_{k 2}}{2}
$$

The equation of centerline $b-b$ (groove 2 ) is written in the following form:

$$
y_{i(b-b)}=-\operatorname{tg}\left(90-\frac{\alpha_{k 2}}{2}\right) \cdot x_{i}-\frac{S_{o}-A_{k 1}-A_{k 2}}{2}
$$

The equation of the imprint of side surface $a^{\prime}-a^{\prime}$ (groove 1) is written in the following form:

$$
y_{i\left(a^{\prime}-a^{\prime}\right)}=\operatorname{tg}\left(90-\frac{\alpha_{k 1}}{2}\right) \cdot x_{i}+\frac{S_{o}-A_{k 1}-A_{k 2}}{2}-\frac{\rho_{k}}{\sin \left(\frac{\alpha_{k 1}}{2}\right)}
$$
form:

The equation of the imprint of side surface $b^{\prime}-b^{\prime}$ (groove 2) is written in the following

$$
y_{i\left(b^{\prime}-b^{\prime}\right)}=-\operatorname{tg}\left(90-\frac{\alpha_{k 2}}{2}\right) \cdot x_{i}-\frac{S_{o}-A_{k 1}-A_{k 2}}{2}+\frac{\rho_{k}}{\sin \left(\frac{\alpha_{k 2}}{2}\right)}
$$

We equate expressions (16) and (17) to find value $x_{i}=\Delta_{x}$, at which values $y_{i\left(a^{\prime}-a^{\prime}\right)}$ and $y_{i\left(b^{\prime}-b^{\prime}\right)}$ will be the same. That is, we find coordinate $x$ of point $B$.

$$
\Delta_{x}=\frac{\rho_{k} \cdot\left(\frac{1}{\sin \left(\frac{\alpha_{k 2}}{2}\right)}+\frac{1}{\sin \left(\frac{\alpha_{k 1}}{2}\right)}\right)-\left(S_{o}-A_{k 1}-A_{k 2}\right)}{\operatorname{tg}\left(90-\frac{\alpha_{k 1}}{2}\right)+\operatorname{tg}\left(90-\frac{\alpha_{k 2}}{2}\right)}
$$




$$
\begin{array}{r}
\text { Substituting the obtained value into Formula (16), we obtain value } \Delta_{y} . \\
\Delta_{y}=\operatorname{tg}\left(90-\frac{\alpha_{k 1}}{2}\right) \cdot \frac{\rho_{k} \cdot\left(\frac{1}{\sin \left(\frac{\alpha_{k 2}}{2}\right)}+\frac{1}{\sin \left(\frac{\alpha_{k 1}}{2}\right)}\right)-\left(S_{o}-A_{k 1}-A_{k 2}\right)}{\operatorname{tg}\left(90-\frac{\alpha_{k 1}}{2}\right)+\operatorname{tg}\left(90-\frac{\alpha_{k 2}}{2}\right)}+\frac{S_{o}-A_{k 1}-A_{k 2}}{2}-\frac{\rho_{k}}{\sin \left(\frac{\alpha_{k 1}}{2}\right)}
\end{array}
$$

The formula determines the area of the $A C D B$ trapezoid:

$$
S_{t 1}=\frac{a_{t 1}+b_{t 1}}{2} \cdot \Delta_{h 1}
$$

where $a_{t 1}$ is the length of the lower base of trapezoid $A B$ formed by the intersection of two grooves, $\mathrm{mm}, b_{t 1}$ is the length of the lower base of trapezoid $C D$ formed by the intersection of two grooves, $\mathrm{mm} ; \Delta_{h 1}$ is the height of the trapezoid formed by the intersection of two grooves, $\mathrm{mm}$.

$$
\Delta_{h 1}=\rho_{k} \cdot \sin \left(\alpha_{k 1} / 2\right)-\frac{S_{o}-A_{k 1}-A_{k 2}}{2}+\Delta_{y}
$$

Formula (20) for determining the area of trapezoid $A C D B$ is written as:

$$
S_{t 1}=\left[2 \cdot \Delta_{x}-\Delta_{h 1} \cdot \operatorname{tg}\left(\alpha_{k 1} / 2\right)\right] \cdot \Delta_{h 1}
$$

Taking into account Formula (18), Formula (22) will be written as follows:

$$
S_{t 1}=\left[\frac{2 \rho_{k} \cdot\left(\frac{1}{\sin \left(\frac{\alpha_{k 2}}{2}\right)}+\frac{1}{\sin \left(\frac{\alpha_{k 1}}{2}\right)}\right)-2 \cdot\left(S_{o}-A_{k 1}-A_{k 2}\right)}{\operatorname{tg}\left(90-\frac{\alpha_{k 1}}{2}\right)+\operatorname{tg}\left(90-\frac{\alpha_{k 2}}{2}\right)}-\Delta_{h 1} \cdot \operatorname{tg}\left(\alpha_{k 1} / 2\right)\right] \cdot \Delta_{h 1}
$$

Similarly, we find the area of trapezoid ABLE.

$$
\begin{gathered}
\Delta_{h 2}=\rho_{k} \cdot \sin \left(\alpha_{k 2} / 2\right)-\frac{S_{o}-A_{k 1}-A_{k 2}}{2}-\Delta_{y} \\
S_{t 2}=\left[\frac{2 \rho_{k} \cdot\left(\frac{1}{\sin \left(\frac{\alpha_{k 1}}{2}\right)}+\frac{1}{\operatorname{tg}\left(90-\frac{\alpha_{k 2}}{2}\right)}\right)-2 \cdot\left(S_{0}-A_{k 1}-A_{k 2}\right)}{\operatorname{tg}\left(90 \operatorname{tg}\left(90-\frac{\alpha_{k 1}}{2}\right)\right.}-\Delta_{h 2} \cdot \operatorname{tg}\left(\alpha_{k 2} / 2\right)\right] \cdot \Delta_{h 2}
\end{gathered}
$$

The formula found the area of the segment with the $C D$ chord:

$$
S_{s 1}=\frac{\rho_{k}^{2}}{2} \cdot\left[\frac{\pi \cdot\left(180-\alpha_{1}\right)}{180^{\circ}}-\sin \left(180-\alpha_{1}\right)\right]
$$

The formula found the area of the segment with the EL chord:

$$
S_{s 2}=\frac{\rho_{k}^{2}}{2} \cdot\left[\frac{\pi \cdot\left(180-\alpha_{2}\right)}{180^{\circ}}-\sin \left(180-\alpha_{2}\right)\right]
$$

The area of existence for Formula (13) was determined by the limit value of the axial pitch of PRRM, which was determined by the dependence:

$$
2 \cdot \rho_{k} \cdot \sin \left(\frac{\alpha_{k 2}}{2}\right)+A_{k 1}+A_{k 2}>S_{o}>A_{k 1}+A_{k 2}+\rho_{k}\left(1-\frac{1}{\sin \left(\alpha_{k 2} / 2\right)}\right)
$$

Stage III. Consider the option when the intersecting grooves formed one sector on top of one of the grooves (Figure 5). 


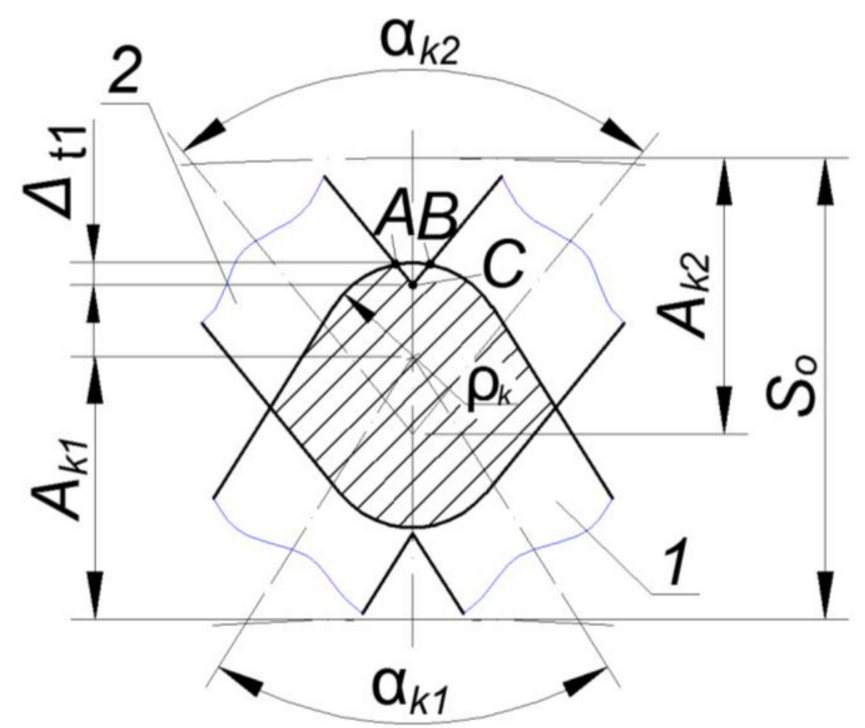

Figure 5. The scheme of overlapping of V-shaped grooves of PRMR (stage III).

The overlap area for this case was calculated by Formula (13), taking into account the absence of the circular sector area with radius $\Delta_{t 1}$, which was determined by the formula:

$$
S_{o v}=S_{s 1}+S_{s 2}+S_{t 1}+S_{t 2}-S_{s 3}
$$

where $S_{s 3}$ is the $A B C$ sector area of the circle formed by the intersection of grooves 1 and 2, $\mathrm{mm}^{2}$.

The area of figures $S_{t 1}$ was determined by Formula (23), $S_{t 2}$-by Formula (25), $S_{s 1}$ - by Formula (26), $S_{s 2}$ - by Formula (27)

The formula determined the area of the $A B C$ sector:

$$
S_{s 3}=\frac{\pi \cdot \Delta_{t 1}^{2} \cdot \alpha_{k 2}}{360}
$$

where $\Delta_{t 1}$ is the radius of sector $A B C, \mathrm{~mm}$.

The formula determined the sector radius:

$$
\Delta_{t 1}=A_{k 1}+A_{k 2}-S_{o}+\rho_{k}\left(1-\frac{1}{\sin \left(\alpha_{k 2} / 2\right)}\right)
$$

Taking into account Formula (31), Formula (30) takes the following form:

$$
S_{s 3}=\frac{\pi \cdot\left[A_{k 1}+A_{k 2}-S_{o}+\rho_{k}\left(1-\frac{1}{\sin \left(\alpha_{k 2} / 2\right)}\right)\right]^{2} \cdot \alpha_{k 2}}{360}
$$

The area of existence for this formula was determined by the limit value of the axial pitch of PRMR, which was determined from the dependence:

$$
\left\{\begin{array}{c}
A_{k 1}+A_{k 2}+\rho_{k}\left(1-\frac{1}{\sin \left(\alpha_{k 2} / 2\right)}\right)>S_{o}>A_{k 1}+A_{k 2}+\rho_{k}\left(1-\frac{1}{\sin \left(\alpha_{k 1} / 2\right)}\right) \\
\alpha_{k 2}>\alpha_{k 1}
\end{array}\right.
$$

Stage IV. Consider the option when the intersecting grooves form circular sectors at the top of each groove (Figure 6). 


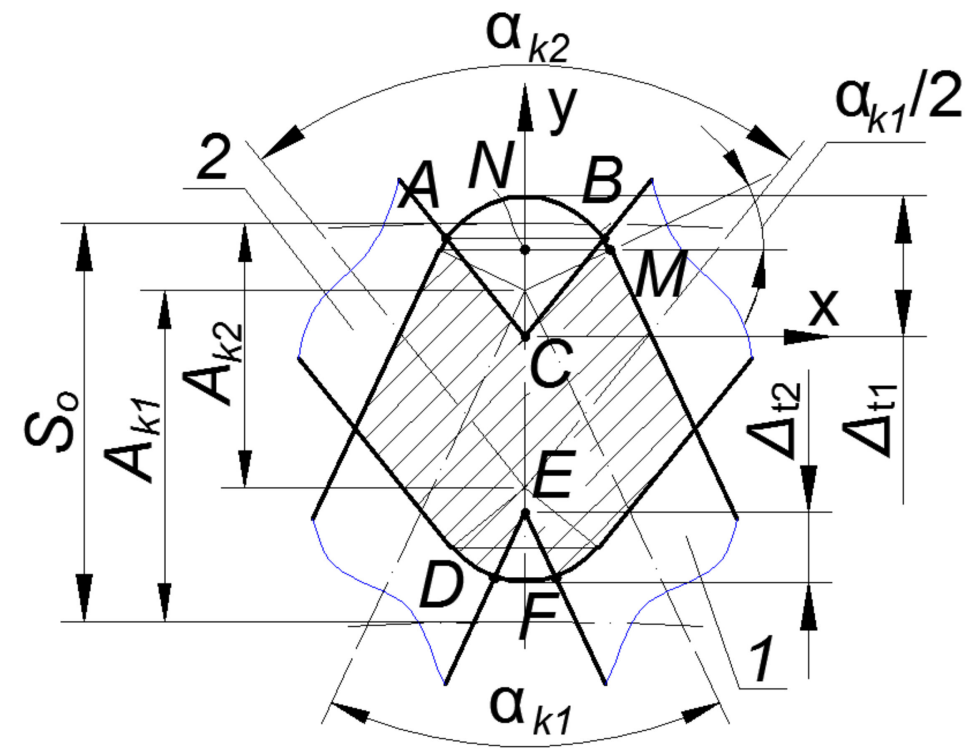

Figure 6. The scheme of overlapping of V-shaped grooves of PRMR (stage IV).

The overlap area for this case was calculated by Formula (13), taking into account the absence of the circular sector area with radii $\Delta_{t 1}$ and $\Delta_{t 2}$, which was determined by the formula:

$$
S_{o v}=S_{s 1}+S_{s 2}+S_{t 1}+S_{t 2}-S_{s 3}-S_{s 4}
$$

where $S_{S 4}$ is the sector area of circle DEF formed by the intersection of grooves 1 and 2, $\mathrm{mm}^{2}$.

The area of figures $S_{t 1}$ is determined by Formula (23), $S_{t 2}$-by Formula (25), $S_{s 1}$ - by Formula (26), $S_{s 2}$-by Formula (27), $S_{s 3}$-by Formula (32).

The formula determined the area of the DEF sector:

$$
S_{s 4}=\frac{\pi \cdot \Delta_{t 2}^{2} \cdot \alpha_{k 1}}{360^{\circ}}
$$

where $\Delta_{t 2}$ is the radius of sector $D E F, \mathrm{~mm}$.

The formula determined the sector radius:

$$
\Delta_{t 2}=A_{k 1}+A_{k 2}-S_{o}+\rho_{k}\left(1-\frac{1}{\sin \left(\alpha_{k 1} / 2\right)}\right)
$$

Taking into account Formula (36), Formula (35) takes the following form:

$$
S_{s 4}=\frac{\pi \cdot\left[A_{k 1}+A_{k 2}-S_{o}+\rho_{k}\left(1-\frac{1}{\sin \left(\alpha_{k 1} / 2\right)}\right)\right]^{2} \cdot \alpha_{k 1}}{360^{\circ}}
$$

The area of existence for this formula was determined by the limit value of the axial pitch of PRMR, which was determined from the dependence:

$$
\left\{\begin{array}{l}
S_{o}>A_{k 1}+A_{k 2}+\rho_{k}\left(1-\frac{1}{\sin \left(\alpha_{k 1} / 2\right)}\right) \\
S_{o}>A_{k 1}+A_{k 2}-\rho_{k}\left(\frac{1}{\sin \left(\alpha_{k 1} / 2\right)}+\frac{1}{\sin \left(\alpha_{k 2} / 2\right)}\right)+\frac{\frac{2 \cdot \rho_{k}}{\sin \left[\left(\alpha_{k 1}+\alpha_{k 2}\right) / 2\right]}-\frac{\rho_{k} \cdot \cos \left(\alpha_{k 2} / 2\right)}{\sin \left(\alpha_{k 1} / 2\right)}}{1-\frac{\operatorname{tg}\left(\alpha_{k 1} / 2\right)}{\operatorname{tg}\left(\alpha_{k 1} / 2\right)+\operatorname{tg}\left(\alpha_{k 2} / 2\right)}} \\
\alpha_{k 2}>\alpha_{k 1}
\end{array}\right.
$$


Stage V. Consider the option when the intersecting grooves form two intersecting diamonds (Figure 7).

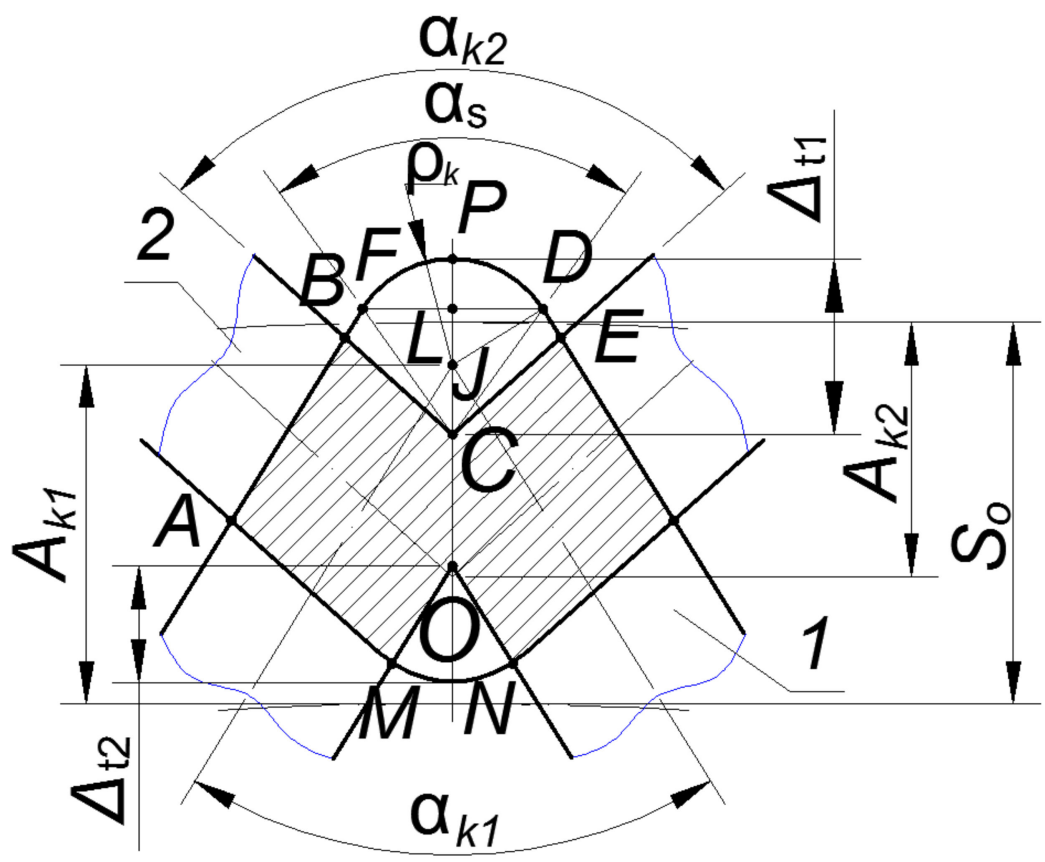

Figure 7. The scheme of overlapping of V-shaped grooves of PRMR (stage V).

The overlap area for this case was calculated by Formula (13), taking into account the absence of the circular sector area with radii $\Delta_{t 1}$ and $\Delta_{t 2}$, which was determined by the formula:

$$
S_{o v}=S_{s 2}+S_{t 1}+S_{t 2}-S_{B C D}-S_{s 4}-2 \cdot S_{C D E}
$$

The area of figures $S_{t 1}$ is determined by Formula (23), $S_{t 2}$ - by Formula (25), $S_{s 2}$ - by Formula (27), $S_{s 4}$-by Formula (37).

Area $\triangle B C D$ was determined by the formula:

$$
S_{B C D}=C L \cdot L D=\left[\Delta_{t 1}-\rho_{k} \cdot\left(1-\sin \left(\frac{\alpha_{k 1}}{2}\right)\right)\right] \cdot \rho_{k} \cdot \cos \left(\frac{\alpha_{k 1}}{2}\right)
$$

Taking into account Formula (31), Formula (40) takes the following form:

$$
S_{B C D}=\left[A_{k 1}+A_{k 2}-S_{o}+\rho_{k}\left(1-\frac{1}{\sin \left(\alpha_{k 2} / 2\right)}\right)-\rho_{k} \cdot\left(1-\sin \left(\frac{\alpha_{k 1}}{2}\right)\right)\right] \cdot \rho_{k} \cdot \cos \left(\frac{\alpha_{k 1}}{2}\right)
$$

Area $\triangle C D E$ was determined by the formula:

$$
S_{C D E}=\frac{1}{2} \cdot C D \cdot C E \cdot \sin \left(\frac{\alpha_{k 1}-\alpha_{s}}{2}\right)
$$

The length of segment $C D$ was determined by the formula:

$$
C D=\frac{\rho_{k} \cdot \cos \left(\alpha_{k 1} / 2\right)}{\sin \left(\alpha_{s} / 2\right)}
$$

The length of segment $C E$ can be found from the sine theorem.

$$
\frac{C D}{\sin \left(\frac{\alpha_{k 1}+\alpha_{k 2}}{2}\right)}=\frac{C E}{\sin \left(\frac{\alpha_{k 1}+\alpha_{k 2}}{2}-\frac{\alpha_{k 2}-\alpha_{s}}{2}\right)}
$$




$$
C E=\frac{\frac{\rho_{k} \cdot \cos \left(\alpha_{k 1} / 2\right)}{\sin \left(\alpha_{s} / 2\right)} \cdot \sin \left(\frac{\alpha_{k 1}+\alpha_{s}}{2}\right)}{\sin \left(\frac{\alpha_{k 1}+\alpha_{k 2}}{2}\right)}
$$

Then Formula (42) for determining area $\triangle C D E$ takes the following form:

$$
S_{C D E}=\frac{1}{2} \cdot \frac{\rho_{k} \cdot \cos \left(\alpha_{k 1} / 2\right)}{\sin \left(\alpha_{s} / 2\right)} \cdot \frac{\frac{\rho_{k} \cdot \cos \left(\alpha_{k 1} / 2\right)}{\sin \left(\alpha_{s} / 2\right)} \cdot \sin \left(\frac{\alpha_{k 1}+\alpha_{s}}{2}\right)}{\sin \left(\frac{\alpha_{k 1}+\alpha_{k 2}}{2}\right)} \cdot \sin \left(\frac{\alpha_{k 1}-\alpha_{s}}{2}\right)
$$

Angle $\alpha_{\mathrm{s}}$ is determined from dependence:

$$
\begin{gathered}
\alpha_{s}=2 \cdot \operatorname{arctg}\left(\frac{L D}{L C}\right) \\
L D=L C \cdot \operatorname{tg}\left(\alpha_{s} / 2\right) \\
L C=A_{k 1}+A_{k 2}-S_{o}+\rho_{k}\left(1-\frac{1}{\sin \left(\alpha_{k 2} / 2\right)}\right)-\rho_{k}\left[1-\sin \left(\alpha_{k 1} / 2\right)\right]
\end{gathered}
$$

Taking into account Formulas (48) and (49), Formula (47) takes the following form:

$$
\alpha_{s}=2 \cdot \operatorname{arctg}\left(\frac{\rho_{k} \cdot \cos \left(\alpha_{k 1} / 2\right)}{A_{k 1}+A_{k 2}-S_{o}-\frac{\rho_{k}}{\sin \left(\alpha_{k 2} / 2\right)}+\rho_{k} \sin \left(\alpha_{k 1} / 2\right)}\right)
$$

The area of existence for this formula was determined by the limit value of the axial pitch of PRMR, which was determined from the dependence:

$$
\left\{\begin{array}{l}
S_{o}>A_{k 1}+A_{k 2}+\rho_{k}\left(\frac{1}{\sin \left(\alpha_{k 1} / 2\right)}+\frac{1}{\sin \left(\alpha_{k 2} / 2\right)}\right)+\frac{\frac{2 \cdot \rho_{k}}{\sin \left[\left(\alpha_{k 1}+\alpha_{k 2}\right) / 2\right]}-\frac{\rho_{k} \cdot \cos \left(\alpha_{k 1} / 2\right)}{\sin \left(\alpha_{k 2} / 2\right)}}{1-\frac{\operatorname{tg}\left(\alpha_{k 2} / 2\right)}{\operatorname{tg}\left(\alpha_{k 1} / 2\right)+\operatorname{tg}\left(\alpha_{k 2} / 2\right)}} \\
S_{o}>A_{k 1}+A_{k 2}-\rho_{k}\left(\frac{1}{\sin \left(\alpha_{k 1} / 2\right)}+\frac{1}{\sin \left(\alpha_{k 2} / 2\right)}\right)+\frac{\frac{2 \cdot \rho_{k}}{\sin \left[\left(\alpha_{k 1}+\alpha_{k 2}\right) / 2\right]}-\frac{\rho_{k} \cdot \cos \left(\alpha_{k 2} / 2\right)}{\sin \left(\alpha_{k 1} / 2\right)}}{1-\frac{\operatorname{tg}\left(\alpha_{k 1} / 2\right)}{\operatorname{tg}\left(\alpha_{k 1} / 2\right)+\operatorname{tg}\left(\alpha_{k 2} / 2\right)}} \\
\alpha_{k 2}>\alpha_{k 1}
\end{array}\right.
$$

Stage VI. Consider the option when intersecting grooves form two intersecting diamonds (Figure 8).

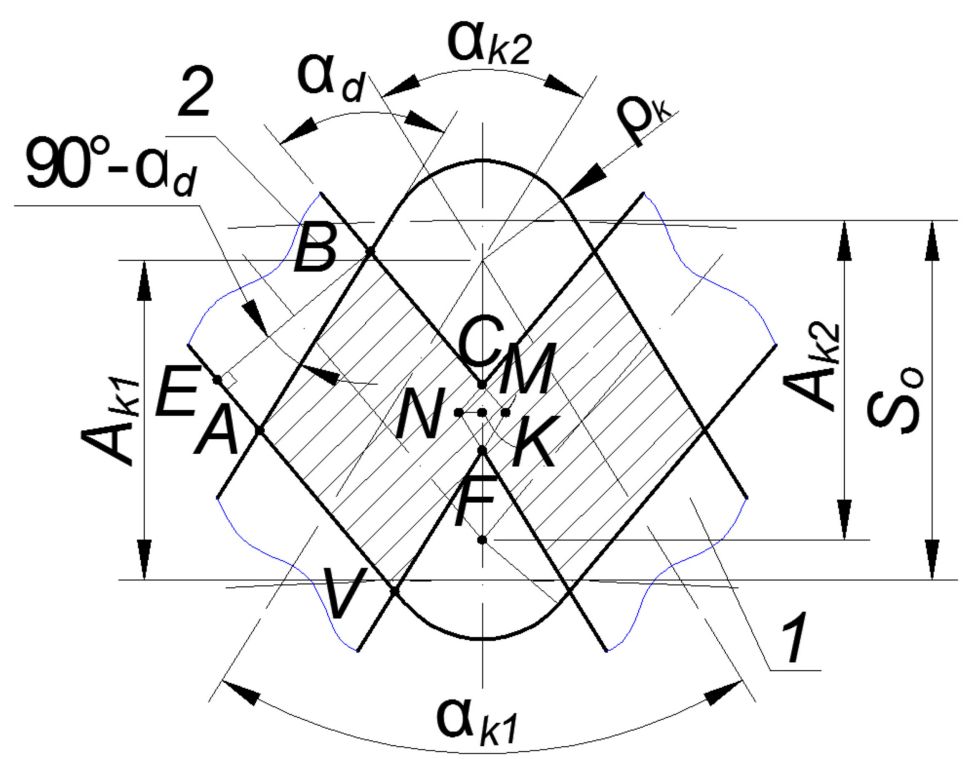

Figure 8. The scheme of overlapping of V-shaped grooves of PRMR (stage VI). 
The overlap area of grooves 1 and 2 in case of their incomplete intersection was calculated as the sum of diamond areas formed as a result of such intersection (Figure 7), except for the area of diamond NCMF, according to the formula:

$$
S_{o v}=2 \cdot S_{R}-S_{r}
$$

where $S_{R}$ is the area of diamond $A B M V, \mathrm{~mm}^{2} ; S_{r}$ is the area of diamond $N C M F, \mathrm{~mm}^{2}$.

$$
S_{R}=b_{d}^{2} \cdot \sin \left(\alpha_{d}\right)
$$

where $b_{d}$ is the length of side $A B$ of diamond $A B M V$, mm;

$\alpha_{d}$ is the central angle $A B C$ of diamond $A B M V$, degrees;

$$
\alpha_{d}=\frac{\alpha_{k 1}+\alpha_{k 2}}{2}
$$

From triangle $A B E$

$$
\begin{gathered}
b_{d}=\frac{2 \cdot \rho_{k}}{\cos \left(90-\frac{\alpha_{k 1}+\alpha_{k 2}}{2}\right)} \\
S_{R}=\left[\frac{2 \cdot \rho_{k}}{\cos \left(90-\frac{\alpha_{k 1}+\alpha_{k 2}}{2}\right)}\right]^{2} \cdot \sin \left(\frac{\alpha_{k 1}+\alpha_{k 2}}{2}\right)
\end{gathered}
$$

After reductions we obtain:

$$
S_{R}=\frac{4 \cdot \rho_{k}^{2}}{\sin \left(\frac{\alpha_{k 1}+\alpha_{k 2}}{2}\right)}
$$

The area of diamond NCMF is determined by the formula:

$$
\begin{gathered}
S_{r}=\frac{C F^{2}}{\operatorname{ctg}\left(\frac{\alpha_{k 1}}{2}\right)+\operatorname{ctg}\left(\frac{\alpha_{k 2}}{2}\right)} \\
C F=S_{0}-A_{k 1}-A_{k 2}+\rho_{k}\left(\frac{1}{\sin \left(\alpha_{k 1} / 2\right)}+\frac{1}{\sin \left(\alpha_{k 2} / 2\right)}\right)
\end{gathered}
$$

Taking into account Formula (59), Formula (58) takes the following form:

$$
\begin{gathered}
S_{r}=\frac{\left[S_{0}-A_{k 1}-A_{k 2}+\rho_{k}\left(\frac{1}{\sin \left(\alpha_{k 1} / 2\right)}+\frac{1}{\sin \left(\alpha_{k 2} / 2\right)}\right)\right]^{2}}{\operatorname{ctg}\left(\frac{\alpha_{k 1}}{2}\right)+\operatorname{ctg}\left(\frac{\alpha_{k 2}}{2}\right)} \\
S_{o v}=\frac{8 \cdot \rho_{k}^{2}}{\sin \left(\frac{\alpha_{k 1}+\alpha_{k 2}}{2}\right)}-\frac{\left[S_{0}-A_{k 1}-A_{k 2}+\rho_{k}\left(\frac{1}{\sin \left(\alpha_{k 1} / 2\right)}+\frac{1}{\sin \left(\alpha_{k 2} / 2\right)}\right)\right]^{2}}{\operatorname{ctg}\left(\frac{\alpha_{k 1}}{2}\right)+\operatorname{ctg}\left(\frac{\alpha_{k 2}}{2}\right)}
\end{gathered}
$$

The area of existence for this formula was determined by the limit value of the axial pitch of PRMR, which was determined from the dependence:

$$
\left\{\begin{array}{l}
S_{o}>A_{k 1}+A_{k 2}-\rho_{k}\left(\frac{1}{\sin \left(\alpha_{k 1} / 2\right)}+\frac{1}{\sin \left(\alpha_{k 2} / 2\right)}\right) \\
S_{o}<A_{k 1}+A_{k 2}-\rho_{k}\left(\frac{1}{\sin \left(\alpha_{k 1} / 2\right)}+\frac{1}{\sin \left(\alpha_{k 2} / 2\right)}\right)+\frac{\frac{2 \cdot \rho_{k}}{\sin \left[\left(\alpha_{k 1}+\alpha_{k 2}\right) / 2\right]}-\frac{\rho_{k} \cdot \cos \left(\alpha_{k 1} / 2\right)}{\sin \left(\alpha_{k 2} / 2\right)}}{1-\frac{\operatorname{tg}\left(\alpha_{k 2} / 2\right)}{\operatorname{tg}\left(\alpha_{k 1} / 2\right)+\operatorname{tg}\left(\alpha_{k 2} / 2\right)}} \\
\alpha_{k 2}>\alpha_{k 1}
\end{array}\right.
$$

Stage VII. Consider the options when intersecting grooves form two diamonds that do not intersect (Figure 9). 


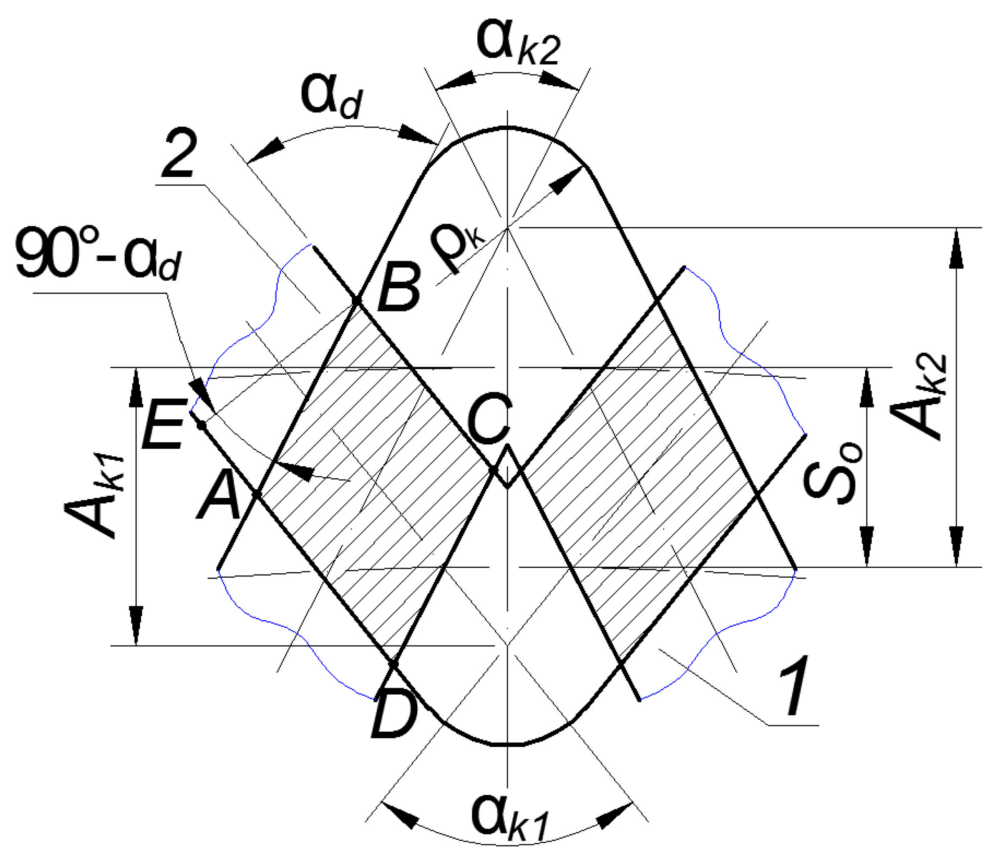

Figure 9. The scheme of overlapping of V-shaped grooves of PRMR (stage VII).

The overlap area of grooves 1 and 2 in case of their full intersection was calculated as the sum of the diamond areas formed as a result of such intersection (Figure 7) according to the formula:

$$
S_{o v}=2 \cdot b_{d}^{2} \cdot \sin \left(\alpha_{d}\right)
$$

where $b_{d}$ is the length of side $A B$ of diamond $A B C D, \mathrm{~mm} ; \alpha_{d}$ is the central angle $A B C$ of diamond $A B C D$, degrees;

$$
\alpha_{d}=\frac{\alpha_{k 1}+\alpha_{k 2}}{2}
$$

From triangle $A B E$

$$
\begin{gathered}
b_{d}=\frac{2 \cdot \rho_{k}}{\cos \left(90-\frac{\alpha_{k 1}+\alpha_{k 2}}{2}\right)} \\
S_{o v}=2 \cdot\left[\frac{2 \cdot \rho_{k}}{\cos \left(90-\frac{\alpha_{k 1}+\alpha_{k 2}}{2}\right)}\right]^{2} \cdot \sin \left(\frac{\alpha_{k 1}+\alpha_{k 2}}{2}\right)
\end{gathered}
$$

After reductions we obtain:

$$
S_{o v}=\frac{8 \cdot \rho_{k}^{2}}{\sin \left(\frac{\alpha_{k 1}+\alpha_{k 2}}{2}\right)}
$$

The area of existence for this formula was determined by the limit value of the axial pitch of PRMR, which was determined from the dependence:

$$
S_{o}<A_{k 1}+A_{k 2}-\rho_{k}\left(\frac{1}{\sin \left(\alpha_{k 1} / 2\right)}+\frac{1}{\sin \left(\alpha_{k 2} / 2\right)}\right)
$$

To ensure the same performance properties of the surface with a partially regular microrelief formed on the rotary body end surface, grooves should be placed with such axial pitch, at which the relative vibration area of the microrelief will be the same (Figure 10). 


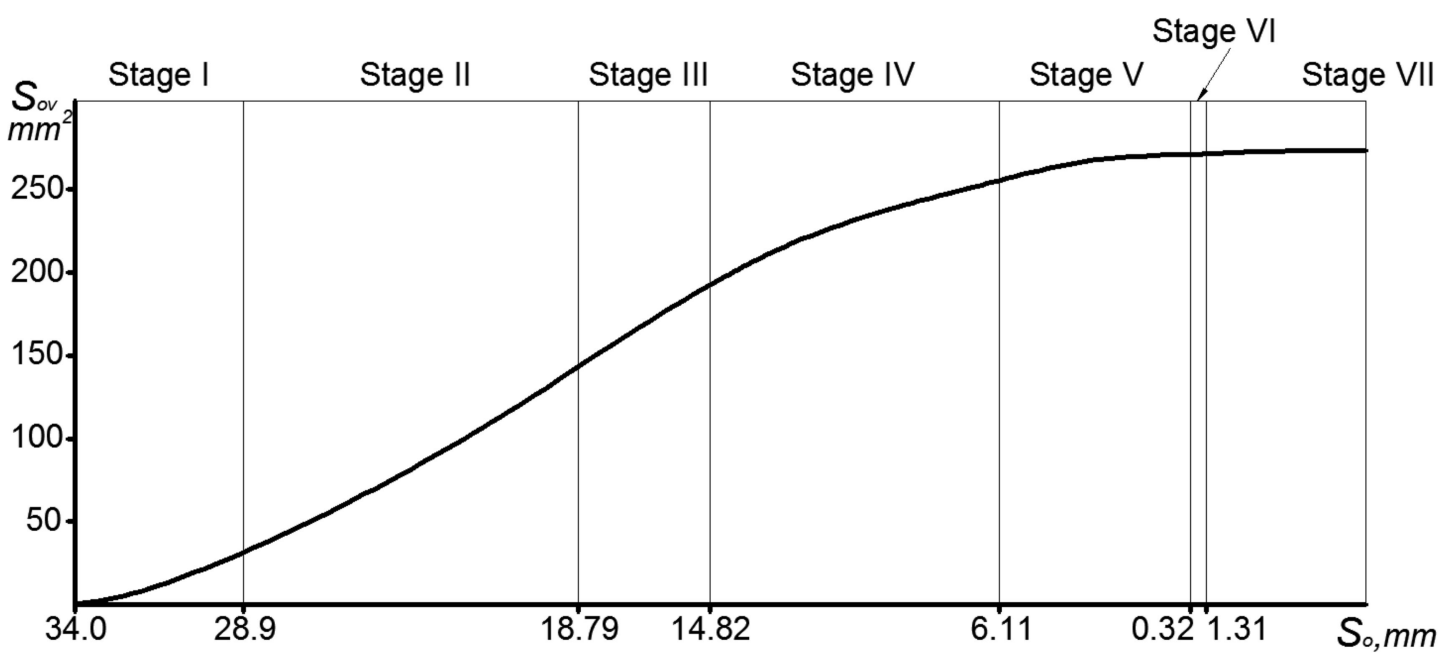

Figure 10. Transformation of the overlap area of V-shaped grooves of partially regular microrelief of the 3rd type shifted by an angular pitch of $0.5^{\circ}$ at $R_{k c 1}=200 \mathrm{~mm} ; A_{k 1}=13 \mathrm{~mm} ; A_{k 2}=11 \mathrm{~mm} ; \rho_{k}=5 \mathrm{~mm} ; \phi_{k}=6^{\circ}$.

Having obtained formulas for determining the overlap area of the grooves and their existence conditions, we can develop an algorithm for finding the optimal value of the axial pitch $S_{\text {oopt }}$ (Figure 11). The optimization criterion will be $F_{n}$ (the relative area of burnishing), which should be in the range of $30-45 \%$.

The numbers of formulas by which the corresponding values should be calculated are given in parentheses in Figure 11.

The following symbols are also used in the block diagram:

$F_{k}$ is the groove area formed on the rotary body end surface [30];

$F_{\text {sur }}$ is the end surface area, on which the regular microrelief is formed;

$F_{r m}$ is the groove area formed on a regular microrelief, taking into account the overlap area;

$F_{n}$ is the relative area of burnishing obtained in [1].

$a$ is the discrete value of the variation of axial pitch $S_{o}$ (which is accepted depending on technical possibilities of the equipment, on which the regular microrelief is formed).

The algorithm for determining the optimal value of the axial pitch $S_{0}$ is as follows:

The user enters the initial data (module 2), in particular, the amplitude of oscillations $A_{k}$, the number of the groove elements $N_{e l}$, the radius of RMR elements arrangement $R_{k \mathrm{c}}$, the imprint radius $\rho_{k}$, the axial pitch $S_{0}$.

The value of variable $S_{o i}$ is assigned to the value of $S_{0}$ (the axial pitch of the grooves) (module 3).

The system compares the axial pitch value with the RMR formation condition, on which V-shaped grooves of partially regular microrelief of the 3rd type shifted by an angular pitch of $0.5^{\circ}$ (module 4 ) are formed, namely:

$$
S_{o i}<A_{k 1}+A_{k 2}+2 \rho_{k}
$$

If this condition is not met, the system issues a message that the condition for the formation of RMR of the 3rd type is not met (module 5). If this condition (module 4) is met, the system checks to which of the seven stages of the overlap process belongs the entered value of the axial pitch $S_{o i}$ (modules $6,8,10,12,14,16,18$ ). When one of these conditions is met, the overlap area of the grooves is calculated according to the formulas from the article, the numbering of which is given in parentheses (modules $7,9,11,13,15,17,19$ ).

If none of these conditions is met, the system issues a message about incorrect data (module 20).

After that, the values included in the formula for determining the relative area of burnishing, in particular, $F_{k}, F_{s u r}, F_{r m}$ (module 21), are determined. Having obtained these 
values, the system recognizes the value of the relative area of burnishing $F_{n}$ and checks whether it is greater than the minimum allowable value of $35 \%$ (module 22). If not, the system increases the $S_{o i}$ variable by value $a$ (module 23), and the process is repeated from module 3.

If the obtained value of the relative burnishing area $F_{n}$ is greater than the minimum allowable value, the system checks whether it is less than the maximum allowable value of $45 \%$ (module 24 ).

If the obtained value of $F_{n}$ is greater than the maximum allowable value, the system reduces the value of $S_{o i}$ by value $a$ (module 25), and the process is repeated from module 3 .

If the obtained value of the relative area of burnishing $F_{n}$ is in the range of $30-45 \%$, the system issues a message that the value of $S_{o i}$ is within optimal limits (module 26).

The intersection of grooves of the partially regular microrelief (type III), which is formed on the end surfaces of rotary bodies, is the most difficult case of their mutual placement, as it has seven different phases. The correctness of determining the relative area of burnishing, which accounts for the performance properties of the formed surface, depends on the correct determination of the intersection area in each of these phases. Therefore, the use of the proposed technique will ensure stable performance properties of the end surface of the rotary body in any part of it.

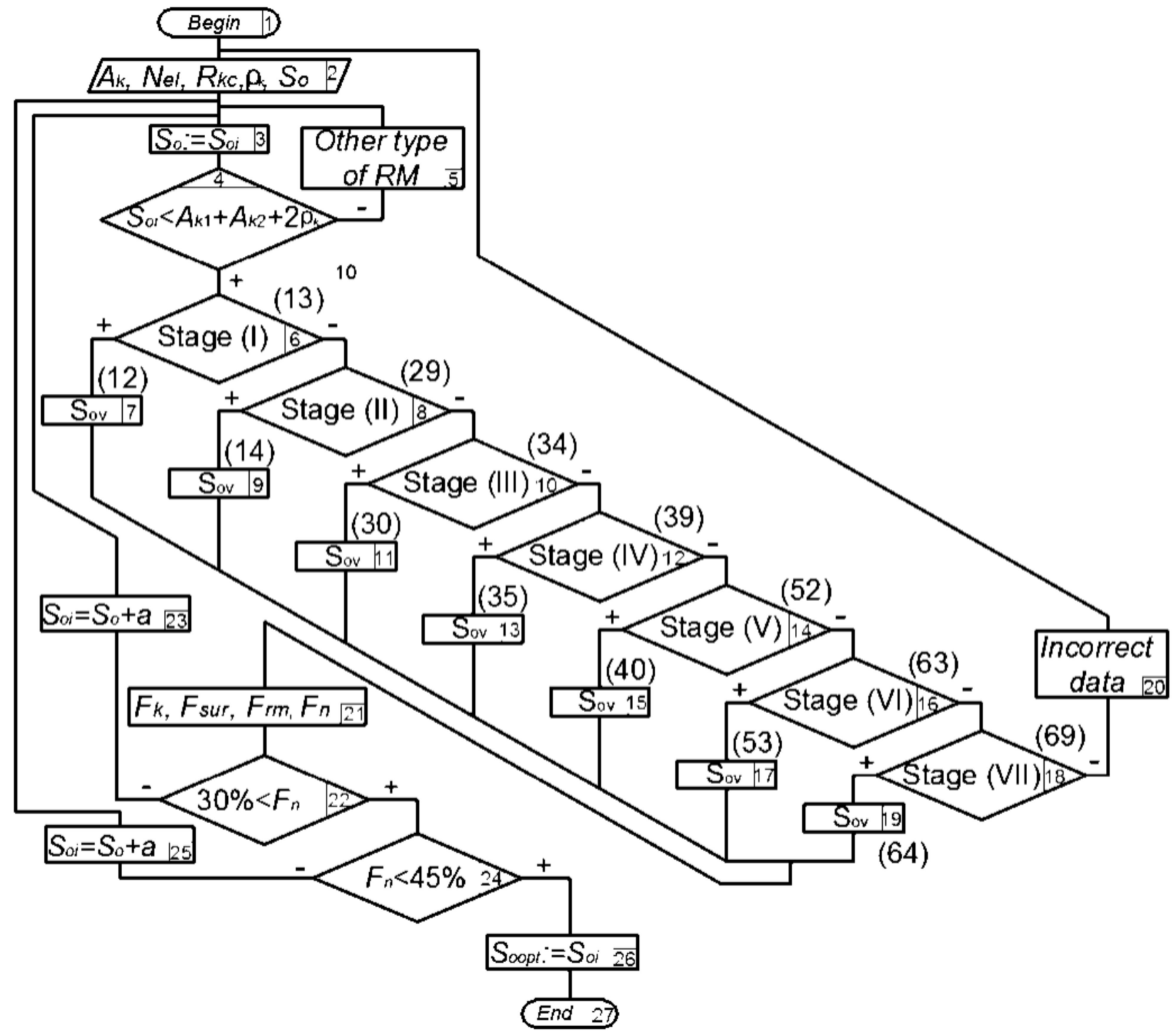

Figure 11. Block diagram of the algorithm for determining the optimal value of axial pitch $S_{o}$. 


\section{Conclusions}

Schemes of the possible mutual arrangement of V-shaped PRMR grooves of the 3rd type formed on RBES are analyzed, the overlap area for each of the schemes considered is defined, and conditions of their existence are established. Changes in this area depending on the axial pitch are found to have a nonlinear character.

The range of values of the axial pitch of the partially regular microrelief for each scheme of mutual arrangement of the PRMR groove elements is determined.

A graphical dependence of the overlap area of the PRMR grooves on the geometric parameters of V-shaped grooves is constructed, which shows that there are overlapping stages, at which the overlap area of the grooves increases rapidly (stages I-IV) or remains nearly unchanged (stages V-VII).

The obtained analytical dependences provide for the required area of burnishing by changing the axial pitch of the PRMR in a given range of values.

An algorithm for determining the optimal value of the axial pitch $S_{o}$ of V-shaped PRMR grooves formed on the end surfaces of rotary bodies is developed.

Author Contributions: Conceptualization, V.D.; methodology, P.M., O.P.; software, V.D.; validation, V.D.; formal analysis, P.M.; investigation, V.D. and P.M.; resources, O.P.; data curation, writingoriginal draft preparation, O.P. and P.M.; writing-review and editing, V.D.; visualization, P.M.; supervision, O.P.; project administration, P.M. and O.P. All authors have read and agreed to the published version of the manuscript.

Funding: This research received no external funding.

Conflicts of Interest: The authors declare no conflict of interest.

\section{References}

1. Schneider, Y.G. Service Properties of Parts with Regular Microrelief, 2nd ed.; Mashinostroenie: Leningrad, Russia, 1982 ; p. 248. (In Russian)

2. Randjelović, S.; Tadić, B.; Todorović, P.; Vukelić, D.; Miloradović, D.; Radenković, M.M.; Tsiafis, C. Modelling of the ball burnishing process with a high-stiffness tool. Int. J. Adv. Manuf. Technol. 2015, 81, 1509-1518. [CrossRef]

3. Nguyen, T.-T.; Cao, L.-H. Optimization of the Burnishing Process for Energy Responses and Surface Properties. Int. J. Precis. Eng. Manuf. 2020, 21, 1143-1152. [CrossRef]

4. Borysenko, D.; Welzel, F.; Karpuschewski, B.; Kundrák, J.; Voropai, V. Simulation of the burnishing process on real surface structures. Precis. Eng. 2021, 68, 166-173. [CrossRef]

5. Hamadache, H.; Zemouri, Z.; Laouar, L.; Dominiak, S. Improvement of surface conditions of 36 Cr Ni Mo 6 steel by ball burnishing process. J. Mech. Sci. Technol. 2014, 28, 1491-1498. [CrossRef]

6. Dzierwa, A.; Markopoulos, A. Influence of Ball-Burnishing Process on Surface Topography Parameters and Tribological Properties of Hardened Steel. Machines 2019, 7, 11. [CrossRef]

7. Basak, H.; Ozkan, M.T.; Toktas, I. Experimental research and ANN modeling on the impact of the ball burnishing process on the mechanical properties of 5083 Al-Mg material. Met. Mater. 2020, 57, 61-74. [CrossRef]

8. Bagherifard, S.; Guagliano, M. Fatigue behavior of a low-alloy steel with nanostructured surface obtained by severe shot peening. Eng. Fract. Mech. 2012, 81, 56-68. [CrossRef]

9. Nagit, G.; Dodun, O.; Slatineanu, L.; Ripanu, M.; Mihalache, A.; Hrituc, A. Influence of some process input factors on the main dimensions of the grooves generated during the ball vibroburnishing. IOP Conf. Series Mater. Sci. Eng. 2020, 968, 012007. [CrossRef]

10. Schulze, V.; Bleicher, F.; Groche, P.; Guo, Y.; Pyun, Y. Surface modification by machine hammer peening and burnishing. CIRP Ann. 2016, 65, 809-832. [CrossRef]

11. Rodriguez, A.; de Lacalle, L.N.L.; Pereira, O.; Fernandez, A.; Ayesta, I. Isotropic finishing of austempered iron casting cylindrical parts by roller burnishing. Int. J. Adv. Manuf. Technol. 2020, 110, 1-9. [CrossRef]

12. Dzionk, S.; Ścibiorski, B.; Przybylski, W. Surface Texture Analysis of Hardened Shafts after Ceramic Ball Burnishing. Materials 2019, 12, 204. [CrossRef] [PubMed]

13. Gavrysh, A.P.; Kirichok, P.O.; Pidbereznyi, M.P. Strengthening of Metal Surfaces of Details of Cars and Mechanisms; Naukova Dumka: Kiev, Ukraine, 1995; p. 174. (In Ukrainian)

14. Patel, D.B.; Patel, T.M. Determination of Optimal Ball Burnishing Parameters for Surface Roughness of Aluminum Alloy. J. Mech Eng. Sci. 2013, 4, 472-478. [CrossRef]

15. Nagîţ, G.; Slătineanu, L.; Dodun, O.; Ionuţ, M.; Andrei, R.; Mihalache, M. Surface layer microhardness and roughness after applying a vibroburnishing process. J. Mater. Res. Technol. 2019, 8, 4333-43466. [CrossRef] 
16. Egea, A.J.S.; Rodríguez, A.; Celentano, D.; Calleja, A.; de Lacalle, L.N.L. Joining metrics enhancement when combining FSW and ball-burnishing in a 2050 aluminium alloy. Surf. Coatings Technol. 2019, 367, 327-335. [CrossRef]

17. GOST 24773-81 Surfaces with Regular Microshape. In Classification, Parameters and Characteristics; Izdatelstvo Standartov: Moscow, Russia, 1988; p. 14. (In Russian)

18. Leshkenova, L.R. Increasing the Productivity of the Processing Process and Improving the Operational Properties of the Surfaces of Holes by the Method of Surface Plastic Deformation with the Formation of a Regular Microrelief. Ph.D. Thesis, Saratov State Technical University, Saratov, Russia, 2002; p. 184.

19. Charfeddine, Y.; Youssef, S.; Sghaier, S.; Sghaier, J.; Hamdi, H. Study of the simultaneous Grinding/Ball-burnishing of AISI 4140 based on finite element simulations and experiments. Int. J. Mech. Sci. 2021, 192, 106097. [CrossRef]

20. Sayahi, M.; Sghaier, S.; Hedi, B.S. Finite element analysis of ball burnishing process: Comparisons between numerical results and experiments. Int. J. Adv. Manuf. Technol. 2012, 67, 1665-1673. [CrossRef]

21. Amini, C.; Jerez-Mesa, R.; Travieso-Rodriguez, J.A.; Llumà, J.; Estevez-Urra, A. Finite Element Analysis of Ball Burnishing on Ball-End Milled Surfaces Considering Their Original Topology and Residual Stress. Metals 2020, 10, 638. [CrossRef]

22. International Organization for Standardization. ISO 8785 Surface Imperfections-Terms, Definitions, and Parameters; International Organization for Standardization: Geneva, Switzerland, 1998; p. 20.

23. Hamdi, A.; Merghache, S.M.; Aliouane, T. Effect of cutting variables on bearing area curve parameters (BAC-P) during hard turning process. Arch. Mech. Eng. 2020, 67, 73-95. [CrossRef]

24. Kubatova, D.; Melichar, M. Roughness Evaluation Using Abbott-Firestone Curve Parameters. In Proceedings of the 29th International DAAAM Symposium, Zadar, Croatia, 24-27 October 2018; pp. 0467-0475.

25. Dzyura, V.O. Modeling of partially regular microreliefs formed on the end faces of rotation bodies by a vibration method. Ukr. J. Mech. Eng. Mater. Sci. 2020, 6, 30-38.

26. Slavov, S.; Dimitrov, D.; Iliev, I. Variability of regular relief cells formed on complex functional surfaces by simul-taneous five-axis ball burnishing. U.P.B. Sci. Bull. Ser. D Mech. Eng. 2020, 82, 195-206.

27. John, M.R.S.; Wilson, A.W.; Bhardwaj, A.P.; Abraham, A.; Vinayagam, B. An investigation of ball burnishing process on CNC lathe using finite element analysis. Simul. Model. Pr. Theory 2016, 62, 88-101. [CrossRef]

28. Slavov, S.; Dimitrov, D. A study for determining the most significant parameters of the ball-burnishing process over some roughness parameters of planar surfaces carried out on CNC milling machine. MATEC Web Conf. 2018, 178, 02005. [CrossRef]

29. Kiselev, M.G.; Korzun, P.O.; Pavich, T.P. Determination of the type of microrelief of the treated surface, providing its largest area and volume in contact with liquid. Bull. P.O. Sykhoi GSTU 2009, 4, 40-52.

30. Dzyura, V.O. Determination of the area of triangular grooves of partially regular microrelief formed on the end surfaces of rotating bodies. Her. Khmelnitskyi Natl. Univ. Tech. Sci. 2020, 283, 62-67. (In Ukrainian)

31. Barauskiene, O.; Zyhulia, S. Optimal control of the complex process of manufacturing cylindrical parts' printing equipment. Tekhnologija Tekhnika Druk. 2019, 4, 42-55.

32. Kyrychok, P.O.; Neskhoziyevskyi, A.V. Research of influence of parameters of a microrelief on quality of processing of a detail and operational characteristics of the printing equipment. Technol. Complexes 2007, 3, 74-80. (In Ukrainian)

33. Pogodayev, V.P. Technological Support of Surface Parameters with Partially Regular Microrelief of Friction Pair Parts. Ph.D. Thesis, Omsk State Technical University, Omsk, Russia, 2004; p. 147. 